


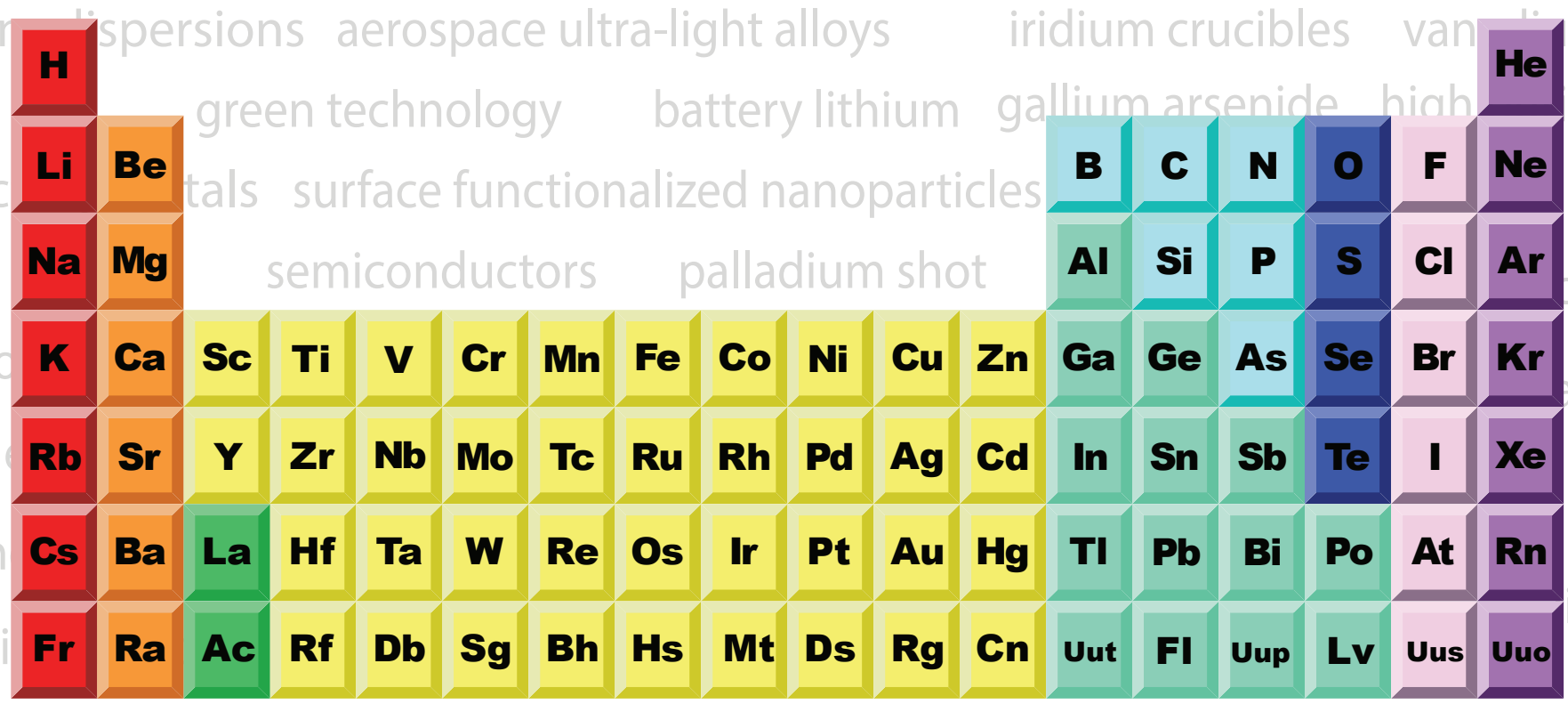

\begin{tabular}{|l|l|l|l|l|l|l|l|l|l|l|l|l|l|l|}
\hline Ce & Pr & Nd & Pm & Sm & Eu & Gd & Tb & Dy & Ho & Er & Tm & Yb & Lu \\
\hline Th & $\mathbf{P a}$ & $\mathbf{U}$ & $\mathbf{N p}$ & $\mathbf{P u}$ & $\mathbf{A m}$ & $\mathbf{C m}$ & $\mathbf{B k}$ & $\mathbf{C f}$ & Es & Fm & Md & No & Lr \\
\hline
\end{tabular}

platinum ink lasercrystals titanium robotic parts tungsten carbide anti-ballistic ceramics fuel cellmaterials hafnium tubing Nd:YAG germanium windows superconductors 99.999\% ruthenium spheres erbium doped fiber optics gadolinium wire

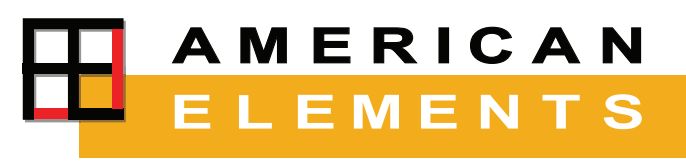

THE MATERIALS SCIENCE COMPANY $®$

\section{catalog: americanelements.com}

@2001-2014. American Eementsisa U.S. Registered Trademark. 